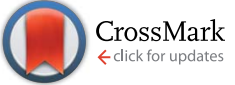

Cite this: RSC Adv., 2016, 6, 49138

\title{
Mechanically strong, flexible and thermally stable graphene oxide/nanocellulosic films with enhanced dielectric properties
}

\author{
Yasir Beeran P. T., ${ }^{\text {abc }}$ Vid Bobnar, ${ }^{d}$ Selestina Gorgieva, ${ }^{a}$ Yves Grohens, ${ }^{c}$ \\ Matjaž Finšgar, , Sabu Thomas*b and Vanja Kokol ${ }^{\star a}$
}

\begin{abstract}
Flexible and eco-friendly films, with enhanced dielectric properties and the potential for energy storage applications, have been fabricated from ammonia-functionalized graphene oxide (NGO) nanoplatelets and wood-based cellulose nanofibrils (CNF) vs. (2,2,6,6-tetramethylpiperidin-1-yl)oxyl (TEMPO) preoxidized (carboxylated) CNFs (TCNF) by the solvent casting method. Various CNF-NGO (CNG) and TCNF-NGO (TCNG) composite films prepared with $0.5-3$ wt\% of NGO were analysed structurally by FTIR and XRD spectroscopy, and evaluated optically by UV-Vis spectroscopy. The morphological analysis using SEM showed good dispersibility of the NGO sheets in the randomly-distributed CNF, and the dense and parallel-oriented TCNF cellulose nanofibrils. Such a synergistic effect of both components contributed to ultra-strong and ultra-stiff composite films with good mechanical and thermal stability, although they were more brittle with a smoother surface and lower transmittance for the TCNF based films, due to the stronger physico-chemical interactions with NGO. The dielectric performance was verified with a higher (3 wt\%) NGO loading capacity, which resulted in a dielectric constant of $\sim 46$ vs. $\sim 52$, and conductivity of $\sim 2.07 \times 10^{-4} \mathrm{~S} \mathrm{~m}^{-1}$ vs. $3.46 \times 10^{-4} \mathrm{~s} \mathrm{~m}^{-1}$ for CNG vs. TCNG films, respectively, at a frequency of $1 \mathrm{MHz}$, showing greater enhancement than other reported studies. Cyclic voltammetry and electrochemical impedance studies reveal the energy storage ability and electrochemical performance of the composite films, under kinetic- and diffusion-controlled processes for the CNG, and under a kinetic-controlled process for the TCNG films.
\end{abstract}

Received 14th March 2016 Accepted 27th April 2016

DOI: $10.1039 / c 6 r a 06744 a$

www.rsc.org/advances

\section{Introduction}

Cellulose materials have recently stimulated significant interest as promising and sustainable substrates in the scientific and industrial fields for their versatile usage in flexible energy storage devices, ${ }^{1}$ transistors, ${ }^{2}$ sensors, ${ }^{3}$ supercapacitors, ${ }^{4}$ etc. Currently, the main strategy in the fabrication of these types of materials with improved dielectric performance is focused on using nano-additives, such as carbon nanotubes and graphene or graphene oxide (GO) nanosheets, due to their ultra-high specific surface area $\left(\sim 2630 \mathrm{~m}^{2} \mathrm{~g}^{-1}\right)$ and excellent electric properties. ${ }^{5}$ However, matrices with a high dielectric constant are crucial for the energy storage materials which, in the case of

${ }^{a}$ University of Maribor, Institute for Engineering Materials and Design, Smetanova ulica 17, 2000 Maribor, Slovenia. E-mail: vanja.kokol@um.si

${ }^{b}$ Mahatma Gandhi University, International and Inter University Centre for Nanoscience and Nanotechnology, 686560 Kottayam, Kerala, India. E-mail: sabuchathukulam@yahoo.co.uk

'Universite de Bretagne, Sud LIMATB Laboratory, Rue St Maude, 56100 Lorient, France ${ }^{d}$ Jožef Stefan Institute, Condensed Matter Physics Department, Jamova 39, 1000 Ljubljana, Slovenia

${ }^{e}$ University of Maribor, Faculty of Chemistry and Chemical Engineering, Smetanova ulica 17, 2000 Maribor, Slovenia cellulose based materials, depend primarily on the cellulose fiber size and porous structure, as indicated by the material free space. ${ }^{6}$ The cellulose/graphene-based nanocomposites with high mechanical and thermal properties are therefore reported as flexible energy storage materials for electronic applications. ${ }^{3,7}$

GO possesses a planar construction with abundant oxygencontaining functional groups (epoxy, hydroxyl and carboxyl) on both basal planes and edges, ${ }^{8,9}$ and aromatic $\mathrm{sp}^{2}$ domains that give it excellent dispersibility in a polymer matrix by generating interfacial bonding. ${ }^{10-12}$ As such, GO has become an effective functional filler in the cellulose matrix. ${ }^{13}$ The presence of a large number of hydroxyl groups of cellulose along the GO skeleton causes the formation of comprehensive networks of intra- and inter-molecular hydrogen bonds with the cellulose, thus forming the two-crystalline and amorphous structural regions in the same polymer. When the polar fillers are uniformly bonded with the neat cellulose, flexible materials are formed. However, the facile aggregation of graphene during synthesis may reduce the material's performance. The low conductivity of GO does not allow for the formation of electronic devices; therefore, reduced GO is largely used for these purposes. Both effects can be minimised by modifying the GO sheets with the proper functional groups, so as to maintain 
strong interactions with the cellulose matrix, ${ }^{5,6}$ as well as to increase the dielectric performances. However, most of the previously reported improvements in dielectric responses for the cellulose/graphene composites ${ }^{\mathbf{6}, 14,15}$ have been focused on the lower frequency regions of the dielectric permittivity of the materials, expressed mainly in the surface layers.

The wood-based cellulose nanofibrils (CNF) and TEMPOoxidized CNFs (TCNF) with ammonia functionalized GO (NGO) were used as highly electroconductive nanofillers, to fabricate flexible energy storage materials. The CNF are an advanced bio-based nanomaterial with high aspect ratio (greater than 250) ${ }^{16}$ and crystallinity, ${ }^{17}$ excellent transmittance, ${ }^{18}$ high flexibility, ${ }^{19}$ as well as superior physical properties, ${ }^{20}$ including high modulus (up to $145 \mathrm{GPa})^{21}$ and low thermal expansivity ( $\left.2.7 \mathrm{ppm} \mathrm{K}^{-1}\right) .{ }^{17}$ The surface structural, mechanical, thermal, transparency and dielectric properties of the composite films were investigated by analyzing the interactions of the NGO within both cellulosic matrices using ATR-FTIR and XRD spectroscopy; analyzing the morphology/topography and surface properties using SEM and contact angle measurements; evaluating the transmittance, tensile strength/stress and TGA; assessing the dielectric constant and conductivity at higher frequency regions, as well as the electrochemical energy storage capacity by cyclic voltammetry and electrochemical impedance studies. The morphology-property correlation was established in order to provide the real intrinsic properties.

\section{Experimental section}

\section{Materials and methods}

Cellulose nanofibrils (CNFs) were obtained from the University of Maine (U.S.A). The ammonia functionalized graphene oxide (NGO with concentration of $1 \mathrm{mg} \mathrm{mL}^{-1}$; Sigma no. 777013), TEMPO reagent, sodium bromide, sodium hypochlorite solution, ethanol (EtOH), and other chemicals were procured from Sigma-Aldrich and used as received.

\section{Preparation of TEMPO-oxidized CNFs (TCNF)}

TEMPO-mediated oxidation of CNF was performed based on the previously reported methods. ${ }^{16,17,22}$ The oxidation solution was prepared by dissolving $0.01475 \mathrm{~g}$ of TEMPO and $0.162 \mathrm{~g} \mathrm{NaBr}$ in distilled water and adding to $1 \mathrm{wt} \%$ of $\mathrm{CNF}$ dispersion. The NaClO solution $(25 \mathrm{~mL}, 10 \%)$ was slowly added to this slurry and stirred at room temperature, and the $\mathrm{pH}$ of the solution was adjusted to 10 and kept constant for $3 \mathrm{~h}$ using $0.1 \mathrm{M} \mathrm{HCl}$ and 0.1 $\mathrm{M} \mathrm{NaOH}$. After stirring for the designated time, the oxidation was quenched by adding $7 \mathrm{~mL}$ of ethanol. The oxidized cellulose was washed thoroughly with water and weighed to measure the mass recovery ratios. The carboxylate content was evaluated by the potentiometric titration method, and increased from $0.3 \pm$ $0.15 \mathrm{mmol} \mathrm{g}^{-1}$ for CNF, to $1.63 \pm 0.21 \mathrm{mmol} \mathrm{g}^{-1}$ for the TCNF.

\section{Fabrication of nanocomposite films}

The NGO/CNF and NGO/TCNF composite films were fabricated by a cost effective solution-casting method. The 3, 6, 12.5, and $19 \mu \mathrm{L}$ of $1 \mathrm{mg} \mathrm{mL}^{-1} \mathrm{NGO}$ aqueous dispersion were mixed with
$50 \mathrm{~mL}$ of $1.2 \mathrm{wt} \% \mathrm{CNF} v$ s. TCNF to get the final concentrations of $0.5 \%, 1 \%, 2 \%$, and $3 \%$, respectively. Pure CNF and TCNF films, without the addition of NGO were made as references. The solutions were mixed with a magnetic stirrer (Tehtnica Rotamix SHP-10) for $15 \mathrm{~min}$, cast on Petri dishes $(120 \times 17$ $\mathrm{mm})$, and dried at room temperature $\left(23 \pm 1{ }^{\circ} \mathrm{C}\right)$ for up to 4 days. The composite films of NGO with CNF were named CNG0.5, CNG-1, CNG-2, and CNG-3, while films prepared with TEMPO-mediated CNF (TCNF) were designated TCNG-0.5, TCNG-1 TCNG-2 and TCNG-3. The average thickness of the CNG and TCNG composite films was in the range of $50 \pm 2 \mu \mathrm{m}$ and $70 \pm 2 \mu \mathrm{m}$, respectively.

\section{Characterization}

Potentiometric titration using a two-burette instrument, Mettler Toledo T70, equipped with a combined glass electrode (Mettler TDG 117) was used to quantify the carboxyl group content of the films. The burettes were filled with $0.1 \mathrm{M} \mathrm{HCl}$ (Merck, Titrisol) and 0.1 $\mathrm{M} \mathrm{KOH}$ (Baker, Dilut-it). Titration was carried out at room temperature $\left(23 \pm 1{ }^{\circ} \mathrm{C}\right)$ in forward and backward runs between $\mathrm{pH} 2.5$ and 11, in an inert ( $\mathrm{N}_{2}$ gas) atmosphere. The quantity of carboxylic groups was determined from the backtitration data.

Attenuated Total Reflectance-Fourier Transform Infrared (ATR-FTIR) spectroscopic analysis was performed to identify the spectral differences associated with the molecular structure of the films, as well as to identify the nature of their interaction. For that purpose, a Perkin-Elmer IR spectrophotometer was used with a Golden Gate Attenuated Total Reflection (ATR) accessory attached to a diamond crystal. The spectra were obtained under ambient conditions from 16 scans at resolutions of $4 \mathrm{~cm}^{-1}$ within the region of $4000-650 \mathrm{~cm}^{-1}$, with air spectrum subtraction performed in parallel as the background. The Spectrum 5.0.2 Software Programme was applied for the data acquisition analysis. A linear baseline was subtracted, and the resulting (absorbance) spectra were normalised before performing the spectral deconvolution in the $\mathrm{OH}$ region (3000$3700 \mathrm{~cm}^{-1}$ ), followed by the Gaussian curve fitting procedure, processed by using Peakfit 4.12 software (Galactic Industries Corporation, New Hampshire, USA). Band position and area were assessed and compared with the reference (CNF and CNF$\mathrm{COOH}$ ) for the composite film with the highest NGO content. The crystallinity of the composite films was determined by using the X-ray Diffraction technique (XRD). The X-ray equatorial diffraction patterns of the composite films were obtained with an X-ray Diffractometer (Bruker Diffractometer D8 Advance Model) using $\mathrm{Cu} \mathrm{K} \alpha$ radiation $(\lambda=0.1539 \mathrm{~nm})$ at the operating voltage and current of $40 \mathrm{kV}$ and $40 \mathrm{~mA}$, respectively, at room temperature $\left(23 \pm 1{ }^{\circ} \mathrm{C}\right)$ within a 2 theta value ranging from $5^{\circ}$ to $55^{\circ}$, and a scan rate of $2^{\circ} \mathrm{min}^{-1}$. The transmittance curves of the films within the $250-750 \mathrm{~nm}$ wavebands were recorded using a Lambda 900 UV-Vis spectrophotometer (Perkin Elmer) with an integrating sphere and scanning speed of $450 \mathrm{~nm}$ $\min ^{-1}$. Field emission SEM imaging was performed using the Ultra + (Zeiss, Germany) microscope to study the morphology. The samples were coated with a platinum layer using an ion 
sputter PECS-Precision etching Coating System, model 682 (Gatan US). Surface characterization and quantification of the films was performed with an ImageJ application for surface assessment, using the SurfCharJ plugin.

Film surface free energy and surface energy components were determined from contact angle (CA) measurements with four pure liquids of different polarities, namely, water, formamide, diiodomethane, and glycerol. Contact Angle (CA) measurements of the films were performed using an SCA20 contact angle measurement system from Dataphysics (Germany). All measurements were conducted at room temperature on two independent surfaces with a test liquid volume of $3 \mathrm{~mL}$. Each CA value was the average of at least eight drops of liquid per surface. The surface free energy (SFE) of the films was calculated from the contact angle values of the test liquids by the van Oss and Good method. ${ }^{23,24}$ The values of the surface tension and the components of the probe liquids used for CA measurements were taken from the Dataphysics database. The total SFE $\left(\gamma_{\mathrm{s}}^{\text {TOT }}\right)$ was calculated using the acid-base approach of van Oss and Good, which divides the total SFE into the dispersive Lifshitz-van der Waals interaction $\left(\gamma_{\mathrm{s}}^{\mathrm{LW}}\right)$ and the polar Lewis acid-base interactions $\left(\gamma_{\mathrm{s}}^{\mathrm{AB}}\right)$, according to the following equations:

$$
\begin{gathered}
\gamma_{\mathrm{s}}^{\mathrm{TOT}}=\gamma_{\mathrm{s}}^{\mathrm{LW}}+\gamma_{\mathrm{s}}^{\mathrm{AB}} \\
\gamma_{\mathrm{s}}^{\mathrm{AB}}=2 \sqrt{ }\left(\gamma_{\mathrm{s}}^{+} \gamma_{\mathrm{s}}^{-}\right)
\end{gathered}
$$

where the Lewis acid-base interactions are subdivided into electron donors $\gamma_{s}^{-}$(Lewis base) and electron acceptors $\gamma_{\mathrm{s}}^{+}$(Lewis acid).

The tensile strength at maximum (MPa) and the tensile strain at break (\%) of the samples were measured using a Shimadzu AGS-X electromechanical universal testing machine. For the testing, the samples were cut into sizes of $1 \mathrm{~cm} \times 5 \mathrm{~cm}$ and mounted vertically with two clamps at a distance of $2.5 \mathrm{~cm}$, and tested at a speed of $1 \mathrm{~mm} \min ^{-1}$ with a $5 \mathrm{kN}$ load cell.

Thermal gravimetric analysis (TGA) was performed by using a STAR Thermogravimetric System, Mettler Toledo under nitrogen purge, with a flow rate of $100 \mathrm{~mL} \mathrm{~min}^{-1}$. The scanning rate was $10{ }^{\circ} \mathrm{C} \mathrm{min}^{-1}$ and the temperature range was from 100 to $800{ }^{\circ} \mathrm{C}$.

For dielectric measurements, film samples were sputtered by $\mathrm{Cr} / \mathrm{Au}$ electrodes with $0.4 \mathrm{~mm}$ diameter (RF magneton sputtering, $5 \mathrm{~Pa}$ ). The capacitance $\mathrm{C}$ and conductivity $\mathrm{G}$ were measured by a Novocontrol Alpha High-Resolution Dielectric Analyzer (Novocontrol Technologies GmbH, Hundsangen, Germany) in the frequency range of $1 \mathrm{kHz}$ to $10 \mathrm{MHz}$, with the amplitude of the probing AC electric signal of $50 \mathrm{mV}$. Then, the real part of the complex dielectric constant, i.e., the dielectric permittivity $\varepsilon^{\prime}$, and the real part of the AC electrical conductivity $\sigma^{\prime}$, were calculated as follows: $\varepsilon^{\prime}=(C d) /\left(\varepsilon_{0} S\right)$ and $\sigma^{\prime}=G d / S$, where $S$ and $d$ are the areas of the electrode and thickness of the film, respectively, and $\varepsilon_{0}$ is the dielectric constant of free space.

Cyclic voltammetry (CV) measurements were performed using a PGSTAT101 controlled by an Autolab Nova Software version 1.8. All experiments were carried out in a $100 \mathrm{~mL}$
Metrohm cell using fabricated film samples of $0.006 \pm 0.0005 \mathrm{~g}$ as the working electrode. A counter (Pt) electrode with an $\mathrm{Ag}$ / $\mathrm{AgCl}$ saturated reference electrode (Metrohm) was used throughout. The electrochemical measurements were performed in $50 \mathrm{~mL}$ of a $1 \mathrm{M} \mathrm{H}_{2} \mathrm{SO}_{4}$ solution serving as the electrolyte. The voltammetric curves were recorded at a scan rate of 5 to $100 \mathrm{mV} \mathrm{s}^{-1}$. The specific capacitance of the electrode was calculated according to the following equation:

$$
C=\frac{1}{m V k} \int_{V-}^{V+} I \mathrm{~d} V
$$

where $C$ is the specific capacitance $\left(\mathrm{F}^{-1}\right), m$ is the mass $(\mathrm{g})$ of the active electrode, $V$ is the potential difference, and $k$ is the scan rate $\left(\mathrm{mV} \mathrm{s}^{-1}\right)$.

Impedance measurements were performed with a Gamry 600 тм potentiostat/galvanostat by using $4 \mathrm{~cm}^{2}$ of film samples as the working electrode. Experiments were performed in a threeelectrode glass cell (volume $1 \mathrm{~L}$ ) closed to the air under stagnant conditions at $25^{\circ} \mathrm{C}$, using $1 \mathrm{M} \mathrm{H}_{2} \mathrm{SO}_{4}$ solution as the electrolyte. A saturated calomel electrode (i.e. SCE, $0.2444 \mathrm{~V} v$ s. SHE) was used as the reference electrode and a Pt mesh as the counter electrode. Spectra were obtained in the frequency range from $0.01 \mathrm{~Hz}$ to $0.1 \mathrm{MHz}$, with 10 points per decade and $5 \mathrm{mV}$ (peak to peak) amplitude of the excitation signal.

\section{Results and discussion}

The structure and morphology of the nanocomposite films were studied to explain their functional properties. The structural composition was identified using FTIR and XRD spectroscopic techniques. The ATR-FTIR spectra of differently fabricated samples are presented in Fig. 1. The NGO shows O-H stretching (broad-coupling hydroxyl group) at $\sim 3230 \mathrm{~cm}^{-1}, \mathrm{C}=\mathrm{O}$ stretching at $\sim 1725 \mathrm{~cm}^{-1}, \mathrm{C}-\mathrm{O}$ alkoxy at $\sim 1376$, and $\mathrm{C}-\mathrm{O}$ epoxy stretching at $\sim 1049 \mathrm{~cm}^{-1}$. Additionally, two peaks were observed at $\sim 1586 \mathrm{~cm}^{-1}$ and $\sim 1224 \mathrm{~cm}^{-1}$, which are attributed to the $\mathrm{N}-\mathrm{H}$ bend and $\mathrm{C}-\mathrm{N}$ stretching, respectively. The typical cellulose-related IR bands at $\sim 3333-3335 \mathrm{~cm}^{-1}, \sim 2900-2923$ $\mathrm{cm}^{-1}, \sim 1318 \mathrm{~cm}^{-1}, \sim 1160 \mathrm{~cm}^{-1}, \sim 1023 \mathrm{~cm}^{-1}, \sim 1028 \mathrm{~cm}^{-1}$ were identified within both CNF and TCNF spectral lines, while the bands at $\sim 1596 \mathrm{~cm}^{-1}$ and $\sim 1739 \mathrm{~cm}^{-1}$ were associated with $\mathrm{C}=\mathrm{O}$ stretching vibrations in carboxylic $\mathrm{COO}^{-}$and the protonated $\mathrm{COOH}$, respectively, identified within the TCNF spectra only. Moreover, the vibration peaks at $\sim 1318 \mathrm{~cm}^{-1}$ indicate the presence of bending vibrations of $\mathrm{C}-\mathrm{H}$ bonds in the cellulose glucose rings, while the peak at $\sim 1023-1028 \mathrm{~cm}^{-1}$ is characteristic of the anhydrous group's $\mathrm{C}-\mathrm{O}$ stretching vibration. In the spectral lines of NGO-embedded CNF/TCNF films, the appearance of relatively weak, yet NGO concentrationdependent vibration lines at $\sim 2918 \mathrm{~cm}^{-1}, \sim 1742 \mathrm{~cm}^{-1}$ and $\sim 1542 \mathrm{~cm}^{-1}$, confirm the NGO presence within the composite films, while the shifting of their position implies their interaction pattern with cellulose.

A closer look at the de-convoluted spectral lines in the region between 3000 and $3700 \mathrm{~cm}^{-1}$ (Fig. 2), revealed the presence of six hidden peaks, related to particular inter- and intramolecular vibrations of $\mathrm{OH}$ groups in the $\mathrm{C}-2, \mathrm{C}-3$ and $\mathrm{C}-6$ 
a)

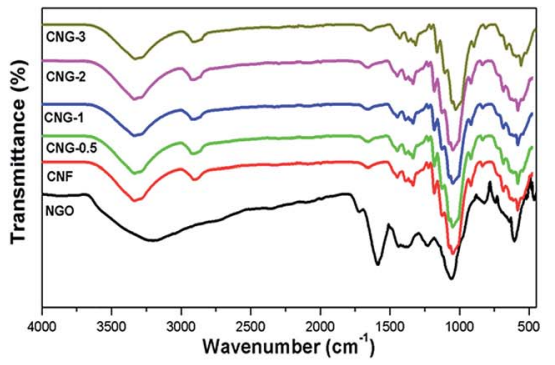

b)

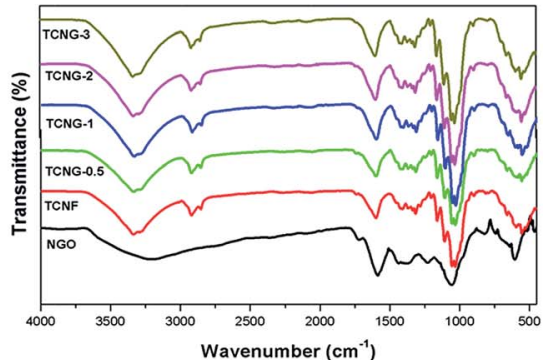

Fig. 1 FTIR spectra of (a) CNG and (b) TCNG composites.

a)
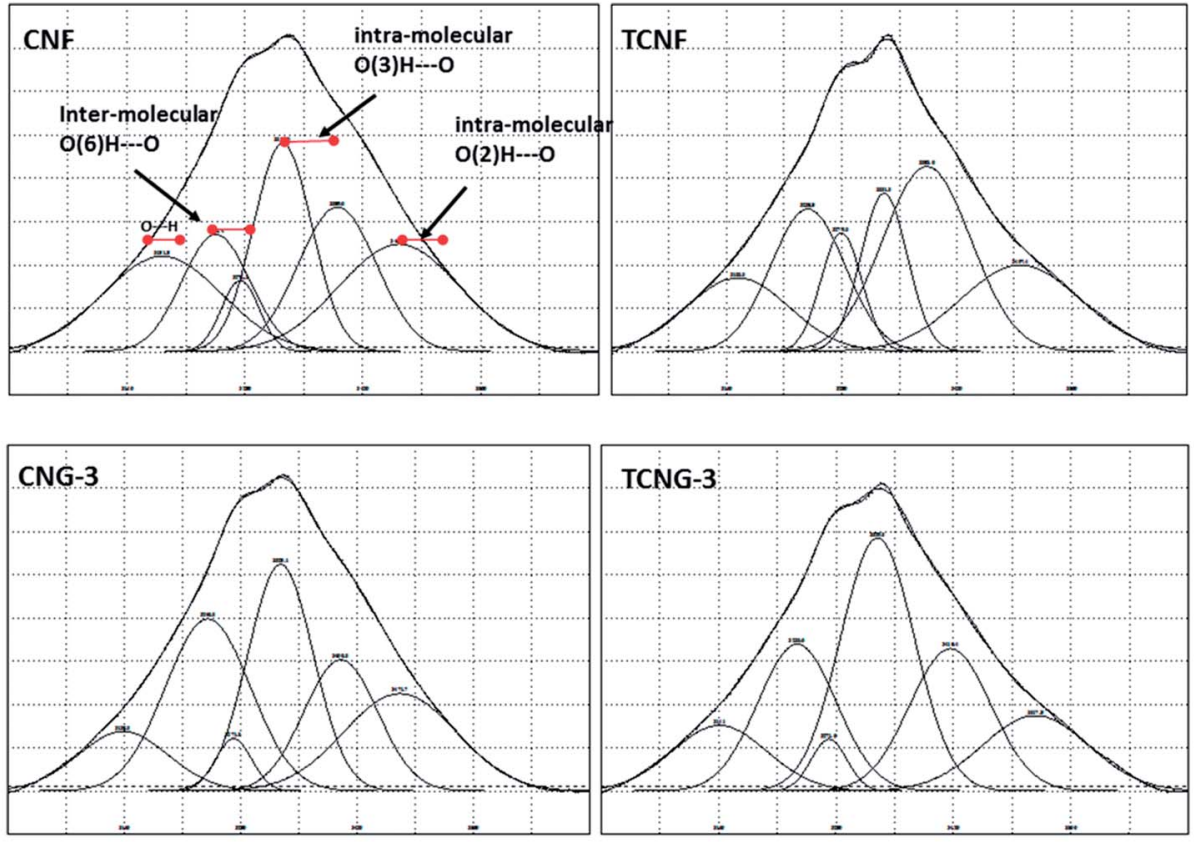

b)

\begin{tabular}{|c|c|c|c|c|c|c|c|c|}
\hline & \multicolumn{2}{|c|}{ CNF } & \multicolumn{2}{c|}{ CNG-3 } & \multicolumn{2}{c|}{ TCNF } & \multicolumn{2}{c|}{ TNG-3 } \\
\hline & $\begin{array}{c}\text { position } \\
\left(\mathrm{cm}^{-1}\right)\end{array}$ & area & $\begin{array}{c}\text { position } \\
\left(\mathrm{cm}^{-1}\right)\end{array}$ & area & $\begin{array}{c}\text { position } \\
\left(\mathrm{cm}^{-1}\right)\end{array}$ & area & $\begin{array}{c}\text { position } \\
\left(\mathrm{cm}^{-1}\right)\end{array}$ & area \\
\hline O-H & 3181.8 & 0.19 & 3138.4 & 0.09 & 3153.5 & 0.13 & 3141.0 & 0.11 \\
\hline \multirow{2}{*}{$\begin{array}{c}\text { Inter-molecular } \\
\text { O(6)H--OO }\end{array}$} & 3245.4 & 0.14 & 3240.5 & 0.25 & 3238.8 & 0.19 & 3233.6 & 0.20 \\
\cline { 2 - 9 } & 3274.3 & 0.04 & 3271.6 & 0.03 & 3279.5 & 0.09 & 3271.6 & 0.03 \\
\hline $\begin{array}{c}\text { intra-molecular } \\
\text { O(3)H---O }\end{array}$ & 3324.6 & 0.21 & 3328.1 & 0.26 & 3331.5 & 0.13 & 3329.5 & 0.32 \\
\cline { 2 - 9 } & 3389.6 & 0.19 & 3400.5 & 0.17 & 3383.6 & 0.29 & 3416.4 & 0.20 \\
\hline $\begin{array}{c}\text { intra-molecular } \\
\text { O(2)H---O }\end{array}$ & 3462.9 & 0.22 & 3471.7 & 0.19 & 3497.4 & 0.18 & 3517.8 & 0.14 \\
\hline
\end{tabular}

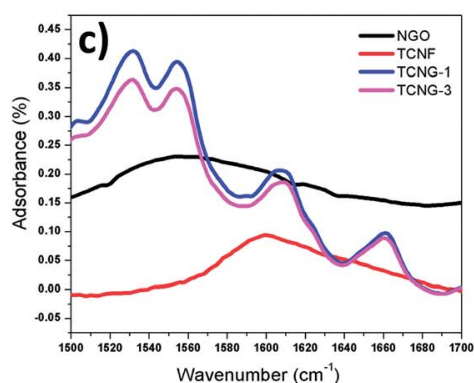

Fig. 2 (a) De-convoluted FTIR spectra in the $v \mathrm{OH}$ region between 3000 and $3700 \mathrm{~cm}^{-1}$; (b) table showing relevant peak positions and areas for CNF and TCNF films without and with the inclusion of $3 \mathrm{wt} \%$ of NGO; (c) de-convoluted FTIR spectra in the range of $1500-1700 \mathrm{~cm}^{-1}$ for NGO, TCNF, TCNG-1 and TCNG-3 composite films.

positions within the glucose ring; ${ }^{25}$ i.e. the $1^{\text {st }}$ peak is attributed to the $\mathrm{O} \cdots \mathrm{H}$ stretching, $2^{\text {nd }}$ and $3^{\text {rd }}$ to the inter-molecular hydrogen bond of $\mathrm{O}(6) \mathrm{H} \cdots \mathrm{O}, 4^{\text {th }}$ and $5^{\text {th }}$ to the intramolecular hydrogen bond of $\mathrm{O}(3) \mathrm{H} \cdots \mathrm{O}$, and $6^{\text {th }}$ to the intramolecular hydrogen bond of $\mathrm{O}(2) \mathrm{H} \cdots \mathrm{O}$. Also observed and supported by calculated data (inserted table in Fig. 2), was the dominant presence of intra-molecular-bonding after the addition of NGO in the TCNF mixture (related to the peaks' total area) over the composite with CNF, while inter-molecular bonding remained almost un-changed. This may imply an interruption of the amorphous cellulosic parts by the NGO, and possible inter-penetration, which allows very close contact among the components, and also mechanical strengthening and dielectric enhancements. 
The involvement of NGO's amino $\left(-\mathrm{NH}_{2}\right)$ surface groups in $\mathrm{H}$-bonding with the $\mathrm{OH}$ and carboxylic groups of TCNF is demonstrated by the $\mathrm{N}-\mathrm{H}$ bend shifting from $\sim 1586 \mathrm{~cm}^{-1}$ to $\sim 1637 \mathrm{~cm}^{-1}$ and by the appearance of three additional bends in these regions, as illustrated in the inserted de-convoluted spectral lines between 1500 and $1700 \mathrm{~cm}^{-1}$, and presented in Scheme 1. In the TCNG composites, the $\mathrm{C}=\mathrm{O}$ stretching vibration peak at $\sim 1596 \mathrm{~cm}^{-1}$ is more intense due to the merging with the $\mathrm{N}-\mathrm{H}$ bend of NGO at $\sim 1586 \mathrm{~cm}^{-1}$. The NGO has interactions with both CNF and TCNF, owing to hydrogen bonding between the carboxyl and OH groups of the NGO and the carbonyl groups of the cellulose matrix. When GO is added to the cellulose matrix, a hydrogen bond occurs between the carbonyl groups of GO and the $\mathrm{OH}$ groups of cellulose, which results in an enhanced interaction, as confirmed by the SEM studies.

The XRD patterns of CNF, TCNF and the nanocomposite films with different NGO loadings are shown in Fig. 3, which reveals interesting facts about the dispersion of NGO and the sample morphology. In the case of CNF and TCNF, two characteristic peaks centred at around $15.5^{\circ}$ and $22.8^{\circ}$ are observed,

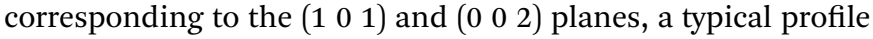
of the cellulose I allomorph. ${ }^{26}$ The broad diffraction peak at $15.5^{\circ}$ indicates the partly crystalline nature of the cellulose. By increasing the amount of NGO in the CNF matrix, a separation of the broader peak at $15.5^{\circ}$ into two, and an intensity decrease in the peak at $22.8^{\circ}$ can be seen, indicating the exfoliation of the layered NGO nanosheets from the cellulose matrix. In the case of TCNF, the XRD spectra are similar, showing the excellently dispersed NGO, without effect on the crystallinity (Table 1).

The light transmittance of neat CNF vs. TCNF and nanocomposite films with embedded NGO were measured by UV-Vis spectroscopy in the region of 250-750 $\mathrm{nm}$ as illustrated in Fig. 4, and the transmittance data are given in Table 2. The CNF spectrum exhibits the highest transmittance ( $\sim 90 \%)$ compared to the TCNF film $(\sim 83 \%)$ in the visible light range (400-800), which may be credited to the presence of the large amounts of carboxyl functional groups in TCNF, as compared to the CNF

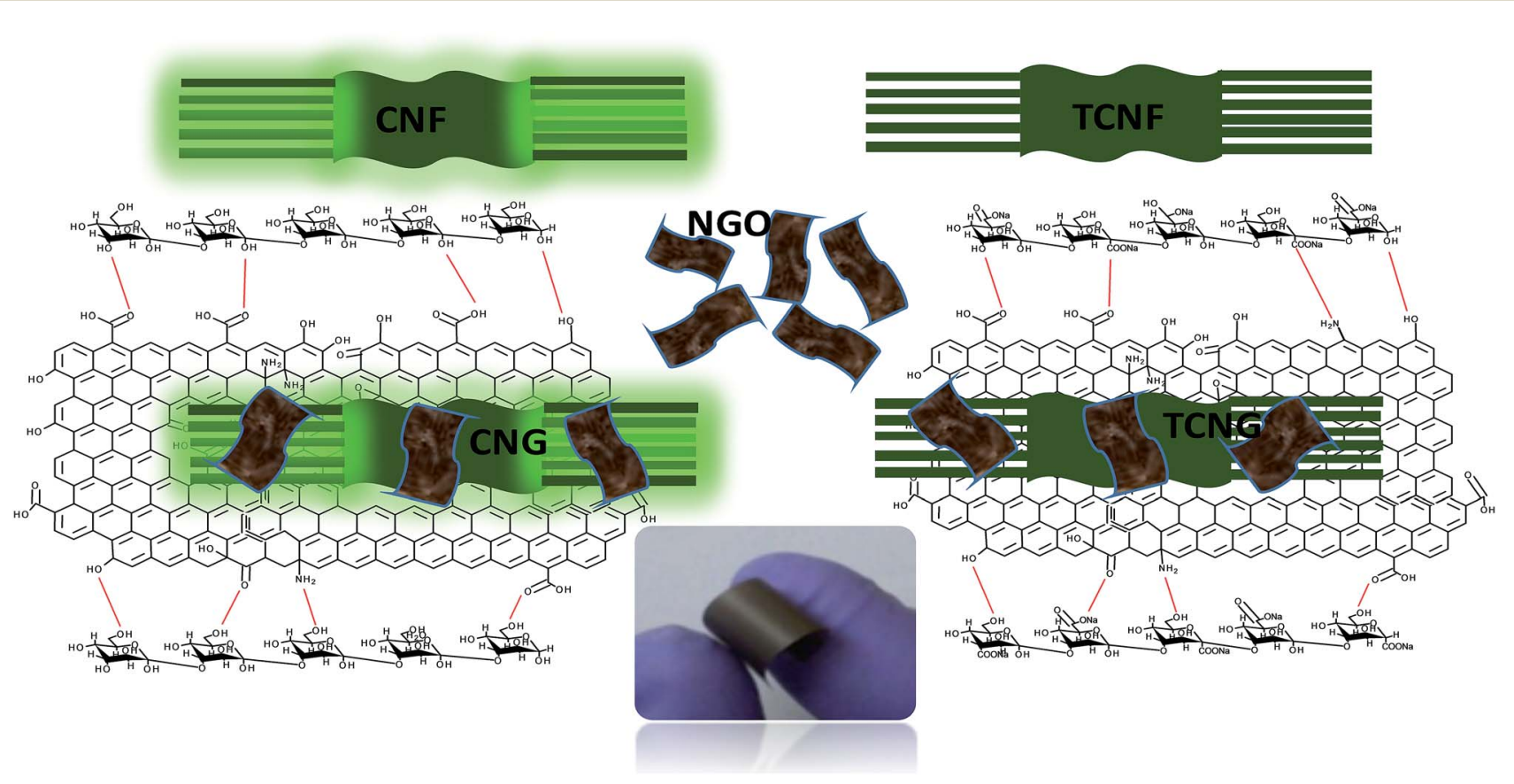

Scheme 1 Schematic of possible interactions of CNF/TCNF with NGO, with inserted digital images of the composite film.
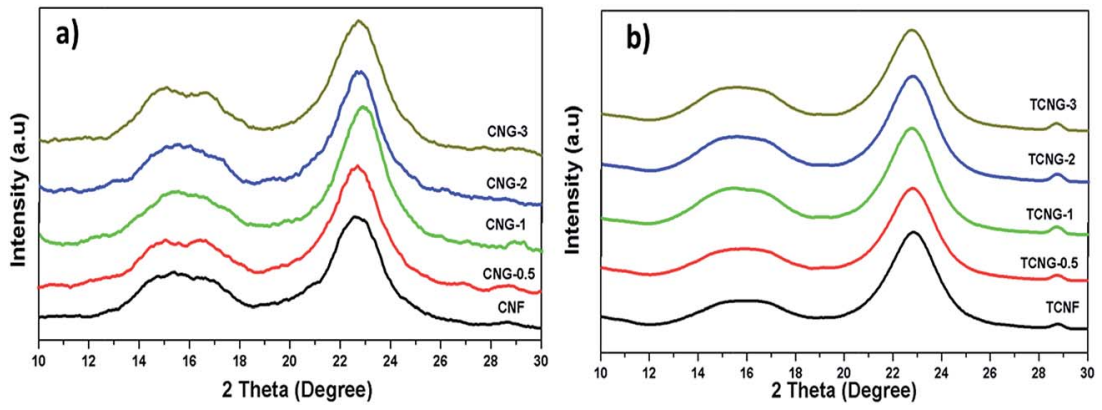

Fig. 3 XRD patterns of (a) CNG and (b) TCNG composite films. 
Table 1 Surface properties (roughness, area, contact angle, surface energy) of native and NGO loaded CNF and TCNF composite films

\begin{tabular}{|c|c|c|c|c|c|c|c|c|c|c|}
\hline Samples & RMS roughness $(\mu \mathrm{m})$ & Surface area $\left(\mu \mathrm{m}^{2}\right)$ & \multicolumn{4}{|c|}{ Contact angle $\theta\left(^{\circ}\right)$} & \multicolumn{4}{|c|}{ Surface energy $\left(\mathrm{mJ} \mathrm{m}^{-2}\right)$} \\
\hline CNG-0.5 & $15.26 \pm 0.11$ & $9.08 \pm 0.09$ & $12 \pm 2$ & $57 \pm 3$ & $56 \pm 3$ & $48 \pm 3$ & $32.70 \pm 1.73$ & $7.11 \pm 1.00$ & $9.58 \pm 2.59$ & $49.20 \pm 5.13$ \\
\hline CNG-1 & $24.13 \pm 0.1$ & $13.33 \pm 0.19$ & $31 \pm 2$ & $62 \pm 3$ & $60 \pm 3$ & $50 \pm 2$ & $30.08 \pm 1.72$ & $4.70 \pm 0.88$ & $10.74 \pm 2.95$ & $44.29 \pm 5.00$ \\
\hline CNG-2 & & & $24 \pm 4$ & $57 \pm 1$ & $55 \pm 2$ & $49 \pm 2$ & $32.03 \pm 1.14$ & $3.47 \pm 0.55$ & $16.26 \pm 1.46$ & $47.05 \pm 3.00$ \\
\hline TCNG-0.5 & $11.4 \pm 0.07$ & $6.42 \pm 0.07$ & $30 \pm 2$ & $57 \pm 2$ & $58 \pm 4$ & $70 \pm 2$ & $37.15 \pm 2.47$ & $1.22 \pm 0.49$ & $18.59 \pm 2.54$ & $46.68 \pm 5.04$ \\
\hline TCNG-1 & $8.28 \pm 0.08$ & $5.33 \pm 0.06$ & $24 \pm 3$ & $62 \pm 3$ & $51 \pm 2$ & $45 \pm 3$ & $33.98 \pm 1.12$ & $4.95 \pm 0.80$ & $8.67 \pm 2.68$ & $47.07 \pm 4.20$ \\
\hline TCNG-2 & & & $31 \pm 1$ & $66 \pm 2$ & $55 \pm 3$ & $43 \pm 3$ & $31.78 \pm 1.69$ & $5.45 \pm 0.82$ & $6.68 \pm 1.59$ & $43.85 \pm 4.03$ \\
\hline TCNG-3 & $7.739 \pm 0.18$ & $4.97 \pm 0.11$ & $31 \pm 1$ & $68 \pm 1$ & $53 \pm 2$ & $53 \pm 2$ & $33.48 \pm 1.13$ & $4.81 \pm 0.51$ & $5.53 \pm 0.77$ & $43.80 \pm 2.39$ \\
\hline
\end{tabular}
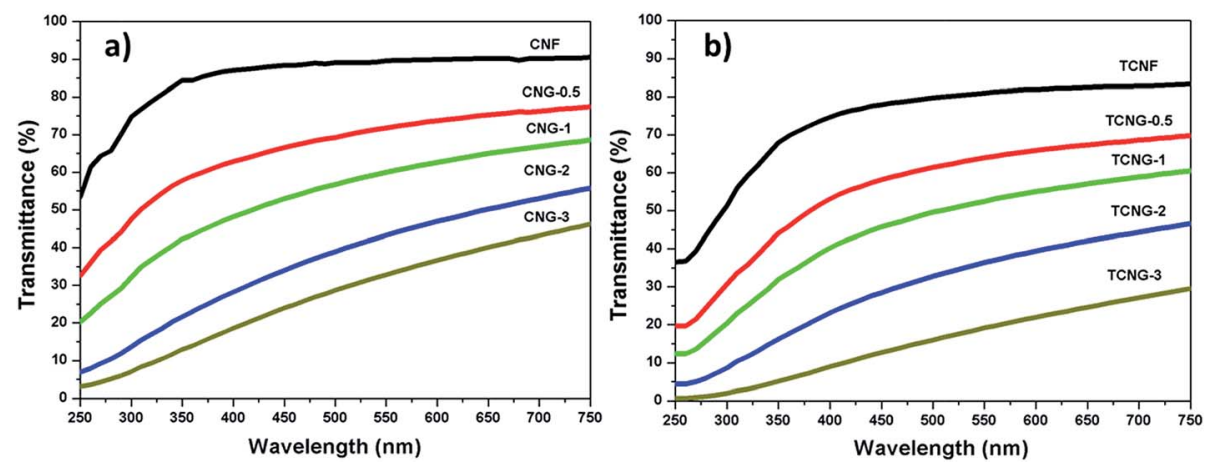

Fig. 4 UV-Visible spectra for (a) CNG and (b) TCNG composite films.

Table 2 Mechanical, transmission and dielectric data of native and NGO loaded CNF and TCNF composite films

\begin{tabular}{|c|c|c|c|c|c|}
\hline Sample & $\begin{array}{l}\text { Tensile strength } \\
\text { (MPa) }\end{array}$ & Strain-to-failure (\%) & $\begin{array}{l}\text { Young's } \\
\text { modulus (MPa) }\end{array}$ & $\begin{array}{l}\text { Transmittance } \\
(\%)\end{array}$ & $\begin{array}{l}\text { Dielectric constant } \\
\text { at } 1 \mathrm{MHz}\end{array}$ \\
\hline $\mathrm{CNF}$ & $59.8 \pm 1.3$ & $93.1 \pm 3$ & $1540 \pm 297$ & 90.5 & 7.54 \\
\hline CNG-1 & $75 \pm 0.5$ & $126.0 \pm 0$ & $2220 \pm 280$ & 69.8 & 38.63 \\
\hline CNG-2 & $78.3 \pm 2$ & $129.7 \pm 1.5$ & $2480 \pm 170$ & 62.9 & 39.14 \\
\hline CNG-3 & $81.5 \pm 1.8$ & $168.37 \pm 3$ & $2920 \pm 155$ & 46.2 & 46.01 \\
\hline TCNG-1 & $78.8 \pm 0$ & $50.3 \pm 0.3$ & $3040 \pm 52$ & 60.4 & 30.97 \\
\hline TCNG-2 & $83.3 \pm 1.2$ & $66.4 \pm 0.8$ & $3190 \pm 95$ & 46.6 & 31.70 \\
\hline TCNG-3 & $88.3 \pm 2$ & $57.01 \pm 0.5$ & $3390 \pm 164$ & 29.5 & 51.46 \\
\hline
\end{tabular}

matrix. The transparency of all composite films decreased with an increment of NGO content, which is more prominent in the case of TCNG composite films as compared to the CNG films, leading to $\sim 30 \%$ and $\sim 46 \%$ transparency with the addition of 3 wt\% of NGO. Another decrease in transmittance with NGO loading may be due to the light scattering effect at the interface of cellulose/GO and their defects, as well as the number of graphene layers and the composite films.

SEM analysis of the film surfaces and cross-section was performed to investigate the dispersion quality and the surface morphology of the nanocomposite films. No agglomeration of NGO was observed in the nanocomposites, as illustrated in the images in Fig. 5. However, the cross-section images reveal that the cellulose nanofibrils interacted strongly with the NGOs, also partly leading to the nanofibrils entangling, as seen by the more compact and dense network structure. At the $3 \mathrm{wt} \%$ of NGO loading, the layers were stacked in a much more compact manner and CNFs became oriented horizontally, expressed more in the TCNF-based composites, due to the interfacial interaction that restrains the $\mathrm{CNF}$ chains and forms chain bridging between individual NGO sheets as already confirmed by the XRD and FTIR spectroscopic study.

The surface structure evaluation (i.e. root mean square roughness and surface area measured with the Surf CharJ 

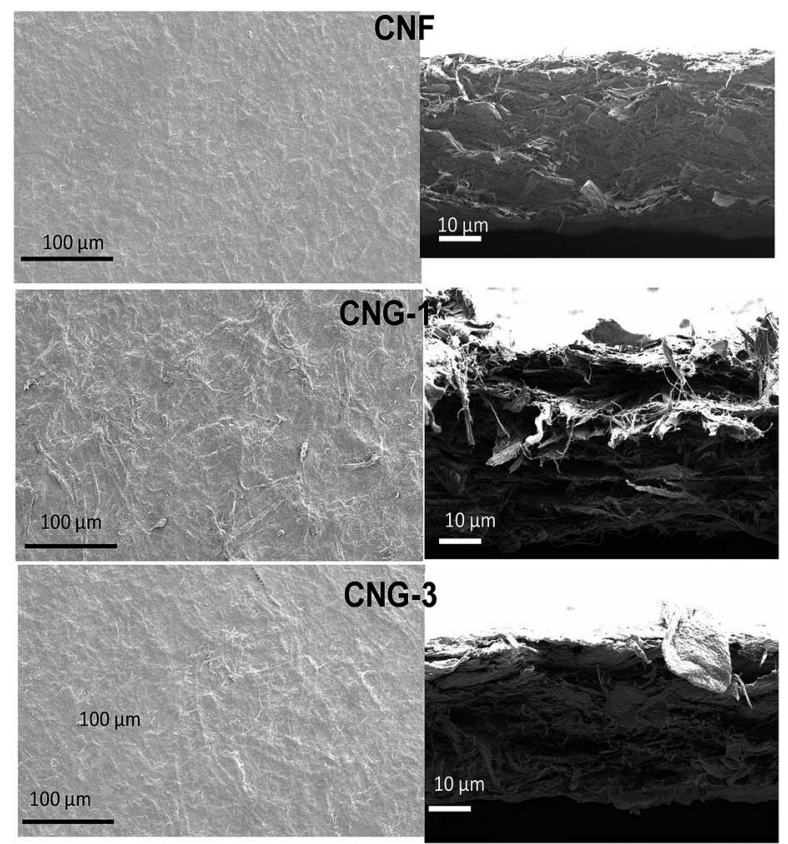

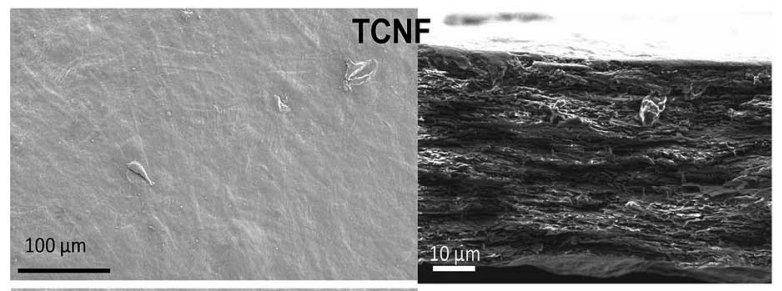

TCNG-1

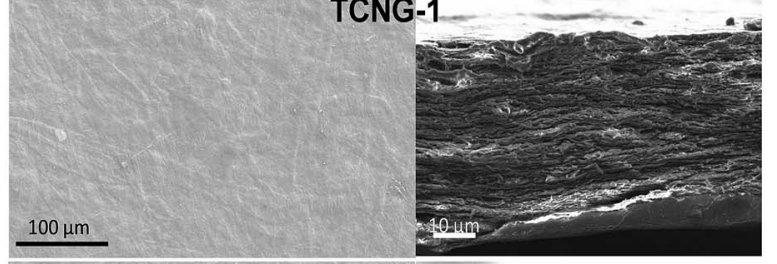

TCNG-3

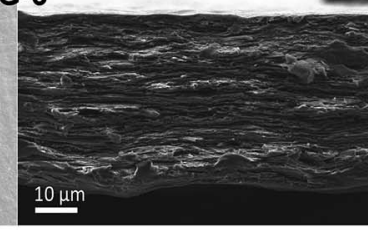

Fig. 5 SEM images of surface (left) and cross-section (right) of native and NGO loaded CNF and TCNF films.

plugin given in Table 2), indicated that both pure CNF and TCNF films show a comparatively smooth surface. By increasing of the NGO loading, the increase in roughness is more significant in the case of CNF as compared to the TCNG based films, being supported by the contact angle measurements, which indirectly indicate the surface wettability properties of the films. The water contact angle of the pure CNF film was found to be lower, compared to the pure TCNF film $\left(\sim 49^{\circ} v s . \sim 55^{\circ}\right)$, which not only suggests the enhancement of the hydrophobicity of the TCNF films, but also reveals the surface microstructure properties of the films. Generally, a smoother surface gives a higher contact angle value than a rough surface, although rough surfaces may also have substantially larger contact angles due to heterogeneous wetting being related to the formation of air compartments between the droplets and the substrate..$^{27,28}$ The incorporation of NGO increased the water contact angles (to $\sim 64^{\circ}$ vs. $\sim 68^{\circ}$ ), which strongly supports that the NGO sheets are exposed directly on the film surfaces by being embedded in the cellulose matrix, leading to an increased surface hydrophobicity of both CNF and TCNF film samples. Also, an increase in the contact angle of the other less polar solutions being tested (above all, formamide from $\sim 5^{\circ}$ to $\sim 29^{\circ}$ in the case of CNF, and from $\sim 25^{\circ}$ to $\sim 31^{\circ}$ in the case of TCNF) support these conclusions.

The addition of NGO influenced not only the contact angle, but also the other surface parameters including surface energy, Lifshitz-van der Waals, Lewis acid and Lewis base components. The total surface free energy $\left(\gamma^{\mathrm{TOT}}\right)$ is similar for CNF and TCNF $\left(\sim 50 \mathrm{~mJ} \mathrm{~m}^{-2}\right)$, is quite high compared to that of NGO incorporated composites, and decreased to around $43 \mathrm{~mJ} \mathrm{~m}^{-2}$ in the case of CNG-3 and TCNG-3 composite films, which correlates well with an increased hydrophobicity. A closer look at the contributions of $\gamma_{\mathrm{s}}^{\mathrm{TOT}}$ gives some interesting facts. There is no significant difference in the Lifshitz-van der Waals component of the film samples, whereas the electron donating contribution $\left(\gamma_{s}^{-}\right)$, which originates from the unsubstituted hydroxyl groups and impurities, decreased with the addition of NGO and was more noticeable at the highest NGO loading. Nevertheless, the acid-base term did not contribute significantly to the total surface free energy of the film samples. The higher value of $\gamma_{\mathrm{s}}^{\mathrm{LW}}$ of the film samples may be attributed to the higher interaction ability of the dispersive part of the $\mathrm{C}-\mathrm{O}$ and $\mathrm{C}-\mathrm{C}$ bonds within the cellulose molecule. ${ }^{29}$

\section{Mechanical properties}

Tensile testing was performed to identify the effect of NGO content on the mechanical properties of the CNF and TCNF film composites. Fig. 6 displays typical stress-strain curves of CNG and TCNG composites with different contents of NGO, and the results are listed in Table 2. Compared to the native CNF, TCNF has about a $25 \%$ increment (from $\sim 59 \mathrm{MPa}$ to $\sim 74 \mathrm{MPa}$ ) in tensile strength and 33\% increment (from $\sim 1540 \mathrm{MPa}$ to 2045 $\mathrm{MPa}$ ) in Young's modulus. This increment in tensile properties may be attributed to the difference in inter-molecular and intramolecular hydrogen bonding patterns of the films, already well defined by FTIR analysis. As such, the enhanced properties of TCNF over CNF provide great potential for the application of ultra-strong and ultra-stiff materials (Fig. 7).

The addition of NGO increased the Young's modulus and tensile strength significantly and as expected, was more intensive in the case of TCNF. The incorporation of NGO into CNF also significantly increased the strain-to-failure (\%), which slightly fluctuated in the composites with TCNF. The CNF-based films are more ductile, compared to the brittle nature of the TCNF-based films, showing an enhanced toughness. However, 

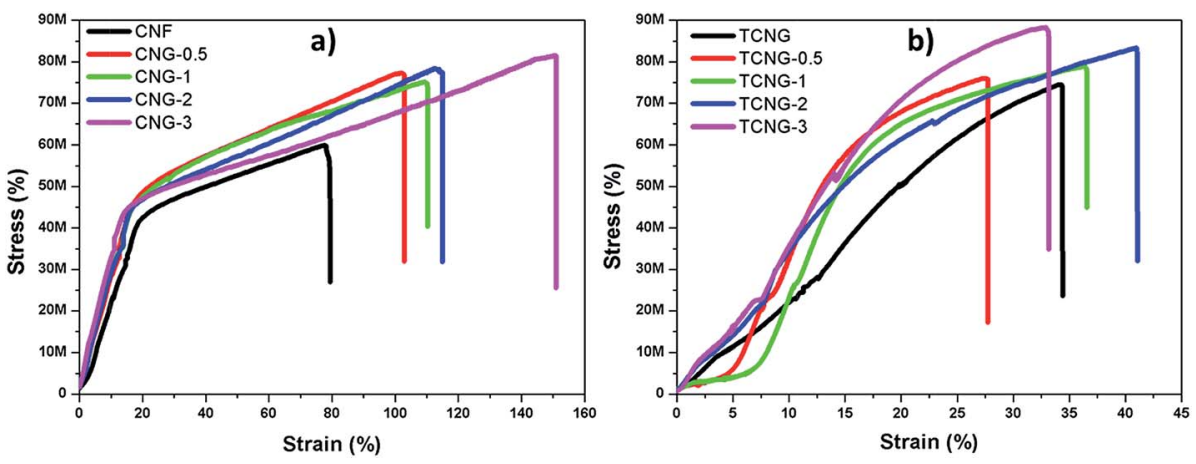

Fig. 6 Stress-strain curves of (a) CNG and (b) TCNG composite films.
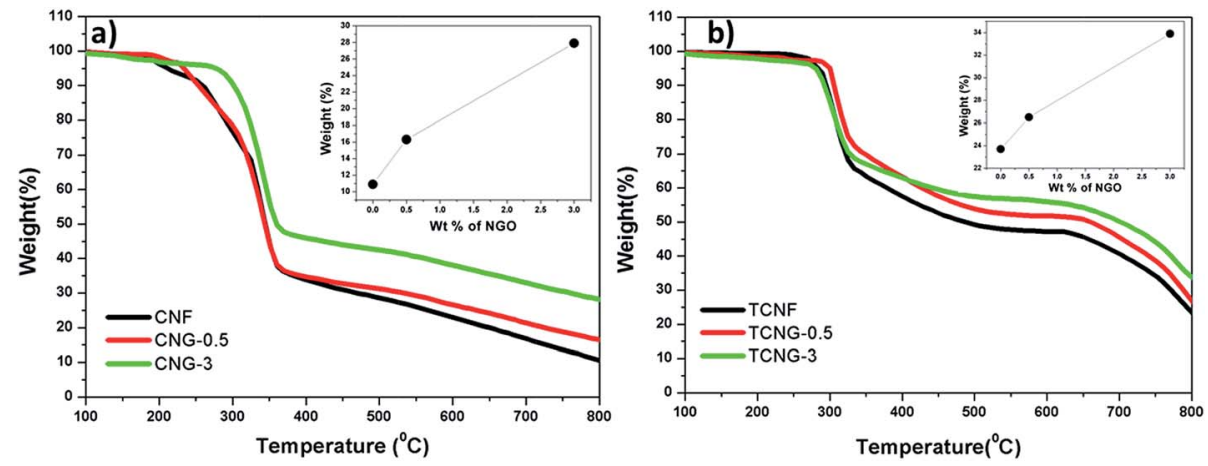

Fig. 7 TGA curves of (a) CNG and (b) TCNG composite films and their carbon yield values at $800^{\circ} \mathrm{C}$, as a function of NGO loading (inset graph).

this phenomenon again illustrates that the reinforcement effect of GO sheets has a close relationship to the dispersion state of NGO in the cellulose matrix. The addition of $0.5 \%$ of NGO into the CNF matrix resulted in an enhanced tensile strength and modulus of $\sim 77 \mathrm{MPa}$ and $\sim 2060 \mathrm{MPa}$, which corresponds to about a $30 \%$ and $34 \%$ increment, respectively, compared to that of the CNF film. At the highest (3 wt\%) NGO loading, both values were further increased to $\sim 81 \mathrm{MPa}$ and $\sim 2920 \mathrm{MPa}$ by using CNF, reaching values of $\sim 88 \mathrm{MPa}$ and $\sim 3390 \mathrm{MPa}$ at TCNF-based film composites, respectively. The observed superior mechanical properties at $3 \mathrm{wt} \%$ of filler loading show significant enhancement, compared to the reported studies. Kim et al. reported a $10.5 \%$ tensile strength enhancement and around $67 \%$ decreased toughness at $3 \mathrm{wt} \%$ of graphene oxide filled cellulose composites with $N$-methylmorpholine- $N$-oxide monohydrate solvent. ${ }^{30}$ B. Wang et al. also studied the mechanical properties of microcrystalline cellulose-graphene oxide composites. At $3 \mathrm{wt} \%$ of $\mathrm{GO}$, the tensile strength increased by $9.6 \%$ and there was a decrease in stress to strain failure of $34 \% .{ }^{12}$ It was generally observed that GO started to aggregate in the polymer composites at the higher loading levels, due to the sheet-to-sheet interaction caused by the inadequate compatibility between the sheet and the polymer chains. $^{31,32}$ The mechanical properties in this work were continuously improved up to $3 \mathrm{wt} \%$ of GO loading in both types of composites, indicating well dispersed and distributed NGO sheets within both the CNF and TCNF matrices as already evidenced by SEM observations.

\section{Thermal properties}

Thermal stability is quite significant in material applications. The thermal properties were evaluated by studying the thermal decomposition behaviours of CNF and TCNF with incorporated NGO fillers, by performing TGA analysis in a nitrogen atmosphere over the temperature range of $100-800{ }^{\circ} \mathrm{C}$. As seen from the thermograms in Fig. 6a the first stage weight loss, which occurred over the temperature range between 125 and $200{ }^{\circ} \mathrm{C}$, resulted from the evaporation of water, and the second weight loss occurred between 200 and $374{ }^{\circ} \mathrm{C}$, being related to the decomposition of the CNF in the composites. ${ }^{33}$ In the case of TCNG composite films (Fig. 6b), the first weight loss occurred between 115 and $230^{\circ} \mathrm{C}$ and the second, between 235 and $344^{\circ} \mathrm{C}$.

The thermal degradation temperature $\left(T_{\mathrm{d}}\right)$ and the carbon yields at $800{ }^{\circ} \mathrm{C}$ for both sets of composites (CNF vs. TCNF based ones) at $3 \mathrm{wt} \%$ of NGO loading were improved, compared to those of the reference. The $T_{\mathrm{d}}$ at $10 \%$ weight loss of CNF was at $\sim 262.4{ }^{\circ} \mathrm{C}$, whereas it increased to $\sim 295.5{ }^{\circ} \mathrm{C}$ for TCNF, indicating the already enhanced thermal stability of the neat matrix material. The addition of NGO to the CNF matrix enhanced the $T_{\mathrm{d}}$ without changing the network of TCNG composites. The carbon yields of CNG-3 ( 28\%) and TCNG-3 ( 34\%) were drastically improved, compared to the neat CNF $(\sim 11 \%)$ and $\operatorname{TCNF}(\sim 24)$, which is accredited to the firm interaction between the cellulose fibrils and GO sheets, as confirmed by FTIR and SEM analysis and mechanical behaviour. The high carbon yield is due to the suppression of the mobility of the cellulose fibrils 
at the interface of the composite films, due to their strong interaction with the NGO loaded sheets. ${ }^{13}$ Such an increment in the carbon yield of the composite materials is a useful property for high temperature applications.

\section{Dielectric studies}

The frequency dependent dielectric constant $\left(\varepsilon^{\prime}\right)$ and conductivity $\left(\sigma^{\prime}\right)$ of the neat CNF $v s$. TCNF matrices and respective NGO embedded composites, measured at room temperature from 10 $\mathrm{Hz}$ to $1 \mathrm{MHz}$, are shown in Fig. 8. The dielectric constant of polymer nanocomposites is the measure of micro-capacitors that are formed by filler particles acting as electrodes filled with insulating matrices, and the polarization centres that are initiated from the defects in the nanofiller structure. ${ }^{34}$ Several reports have been made on the enhancement of the dielectric responses of the cellulose polymer with graphene-based fillers. ${ }^{6,14,15}$ The dielectric properties of cellulose/GO composites were studied by Kafy et al. ${ }^{6}$ at $20 \mathrm{~Hz}$, and they achieved 190 times enhancement for the $3 \mathrm{wt} \%$ GO filled composites, compared to the neat cellulose. Mohiuddin et al. ${ }^{\mathbf{1 4}}$ reported an $80 \%$ increase in the dielectric constant of modified reduced $\mathrm{GO} /$ cellulose acetate composites, compared to the neat cellulose acetate at $150 \mathrm{~Hz}$. Sadasivuni et $a .^{15}$ described the dielectric enhancement of reduced $\mathrm{GO} /$ cellulose films at $22 \mathrm{~Hz}$ and $1 \mathrm{kHz}$ and obtained 44 and 4 times improvement, respectively, over the neat polymer. Similarly, the polyurethane composites filled with $3 \%$ of modified and unmodified GO resulted in dielectric constants of around 17 and 20 at $1 \mathrm{MHz}$ and $10 \mathrm{~Hz}$, respectively, ${ }^{36}$ while dielectric constants of 57.7 and 67.5 at $1 \mathrm{kHz}$ were reported by Y. Li et al. for polyvinylidene fluoride composites with $30 \mathrm{vol} \%$ of GO and reduced-GO encapsulated barium titanate as a hybrid fillers, respectively. ${ }^{35}$

However, all the previous reported studies investigated the dielectric properties of the materials at the lower frequency regions. Generally, the dielectric constant increases with frequency-lowering, due to the space charge contribution. At low frequencies, the external effects, such as the presence of surface layers (for example, due to the formation of Schottky barriers) often govern the dielectric response. ${ }^{37}$ To provide the real, intrinsic material properties, we therefore compared (Fig. 9) the values detected at the highest measured frequencies, i.e. at $1 \mathrm{MHz}$. The $\varepsilon^{\prime}$ values of the CNG-3 and TCNG-3 composite films increased from $\sim 7.5$ and $\sim 9.7$ to $\sim 46$, and $\sim 51.5$, respectively, compared to the neat CNF and TCNF films. The enhancement in dielectric properties in the present study compared to reported studies may be attributed to the improved dispersion effect of graphene oxide fillers and cellulosic matrices, already discussed by mechanical analysis.
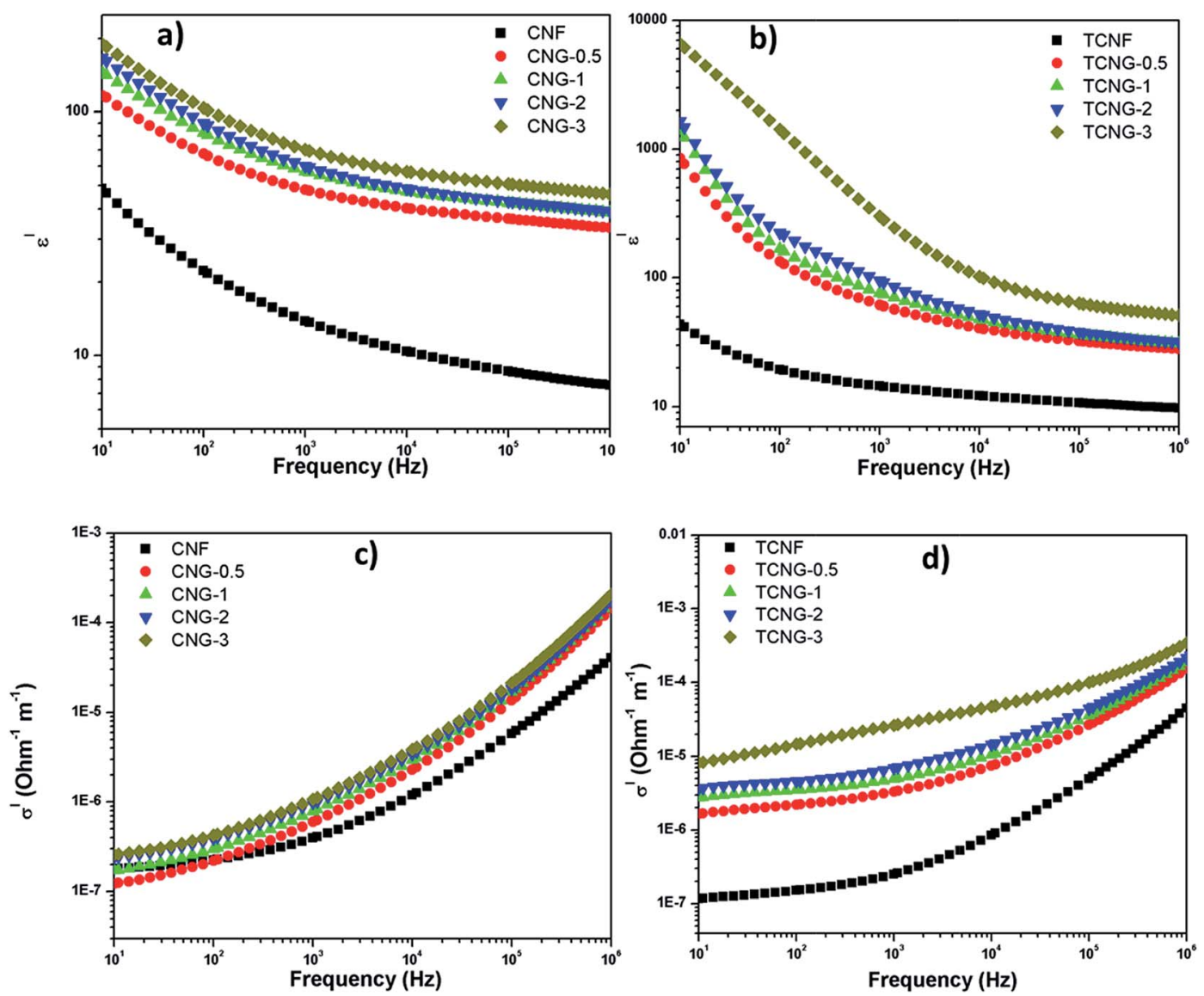

Fig. 8 Frequency dependence of the dielectric constant $\left(\varepsilon^{\prime}\right)$ of (a) CNG and (b) TCNG; ac conductivity ( $\left.\sigma^{\prime}\right)$ of (c) CNG and (d) TCNG composite films measured at room temperature. 

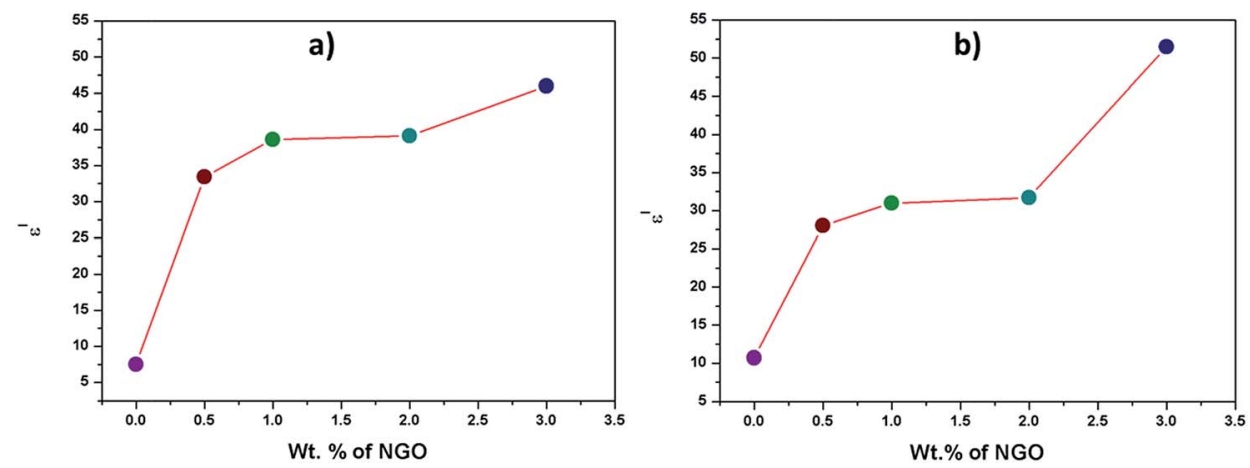

Fig. 9 Evolution of the real part of the dielectric constant $\left(\varepsilon^{\prime}\right)$ at a frequency of $1 \mathrm{MHz}$ vs. NGO loading for (a) CNG and (b) TCNG composite films.

The evolution of the dielectric constant $\left(\varepsilon^{\prime}\right)$ of $\mathrm{CNG}$ and TCNG composite film samples is shown in Fig. 8. The enhancement in the composites originates from the synergetic Maxwell-Wagner-Sillars (MWS) polarization effect, in which the polymer-filler interfacial interaction is necessary to induce changes in the dielectric properties of the nanocomposites. The nanocomposite provides the enormous interfacial area for abundant sites for the reinforced MWS effect. When a current flows across the two-material dielectric interfaces, GO sheets and CNFs matrices, charges accumulate at the interface because of the presence of functional groups and conjugation on the GO sheet surface, which forms an effective capacitor network to store energy. ${ }^{6}$ The presence of an intensive amount of charges in the case of TCNF may be attributed to the enhanced dielectric property of TCNG film samples. This enormous enhancement in dielectric constant by adding NGO sheets into the cellulose matrices can be credited to the greater MWS effect leading to high dielectric permittivity, due to the entrapment of charge carriers in the interface.

AC conductivity $\left(\sigma^{\prime}\right)$ of CNG and TCNG composite films also increased with an increase in the frequency over the whole investigated frequency range, as well as with increases in the NGO content (Fig. 8). At lower frequency, the NGO sheets are effectually blocked, whereas at higher frequencies the charge carriers cannot block the boundaries, giving an effective conductivity. At $1 \mathrm{MHz}$, the composite film showed a $\sigma^{\prime}$ value of $\sim 2.07 \times 10^{-4} \mathrm{~S} \mathrm{~m}^{-1}$ and $\sim 3.46 \times 10^{-4} \mathrm{~S} \mathrm{~m}^{-1}$ for CNG-3 and TCNG-3, respectively. This increment for the TCNG composite film may be related to the formation of a network with more densely and horizontally oriented components, as compared to the CNG network, already well defined by SEM images.

\section{Cyclic voltammetry and electrochemical impedance studies}

The electrochemical behaviour (electron transfer) and charge storage performance were evaluated for the CNG and TCNG films with $3 \mathrm{wt} \%$ of NGO as paper electrodes by cyclic voltammetry (CV), recorded with a three-electrode setup in $1 \mathrm{M} \mathrm{H}_{2} \mathrm{SO}_{4}$ electrolyte solution. The well-defined, quasi-reversible $\left(I_{\mathrm{pc}} / I_{\mathrm{pa}} \leq\right.$ 1) shapes of CV curves (Fig. 10) show that the samples have capacitive behaviour. ${ }^{38}$ Since the discharge current is restricted, the material is more suitable for use as negative electrodes. The reduction peaks around $-0.2 \mathrm{~V}$ in the case of the TCNG-3\% sample shows the excellent reduction effect. Also, a decrease in the specific capacitances (SCs) with increasing scan rates are attributed to the fact that the electrolytic ions cannot be fully adsorbed on the active electrodes because of the low diffusion time. ${ }^{39}$ However, the SCs of the studied cellulose films are comparable to the reported results. Dengteng et al. reported a volumetric capacitance of $40.5 \mathrm{~F} \mathrm{~cm}^{-3}$ and areal capacitance of $0.33 \mathrm{~F} \mathrm{~cm}^{-2}$ for foldable supercapacitor electrodes using macroporous cellulose fibers with single-walled carbon nanotubes/PANI nanowires. ${ }^{40}$ This was attributed to the synergistic effect of electron transport within the SWCNTs network and fast charge transfer of the PANI nanoribbons. ${ }^{40}$ Nanocellulose derived porous carbon aerogels were reported by Guoqing et al., with SC of $205 \mathrm{~F} \mathrm{~g}^{-1}$ reached at a current density of $20 \mathrm{~A} \mathrm{~g}^{-1}$ within a potential window of -1.0 to $0 \mathrm{~V} .^{41}$

Nyquist spectra for both films were measured at an opencircuit potential and are presented in Fig. 10d. The Nyquist plot for TCNG-3\% shows a depressed semi-circuit with no indication of the diffusion process (in the case of diffusion, the measured data would deviate at low frequencies from the $Z_{\text {real }}$ axis). The depressed semi-circuit is usually explained by the inhomogeneity of the electrode (in this case the TCNG film), which occurs due to the random distribution of the nanoparticles. The depressed semi-circuit results from a parallel combination of the charge-transfer resistance and constant phase element (CPE). Therefore, the TCNG-3\% film is under a kinetic-controlled process and can be represented with a $R_{\mathrm{s}}(R Q)$ equivalent electrical circuit, where $R_{\mathrm{s}}$ stands for the solution resistance (resistance of the ion conducting paths that developed inside the film), $R$ stands for the charge-transfer resistance and $Q$ for CPE. The impedance of the CPE is described as $Z(\mathrm{CPE})=\left(Q(j \omega)^{n}\right)^{-1} \cdot{ }^{42}$ The measurement for the CNG-3\% film also shows a depressed semi-circuit, but at the lowest frequencies measured, in addition to the deviation of the measured impedance data from the $Z_{\text {real }}$ axis. This implies that the CNG-3\% film is also under a diffusion-controlled process, due to the ions that migrate into the electrode material, which is associated with capacitive performance. Therefore, the sample CNG-3\% is under kinetic-controlled and diffusion-controlled processes and can be represented with a $R_{\mathrm{s}}(R(Q W))$ equivalent 

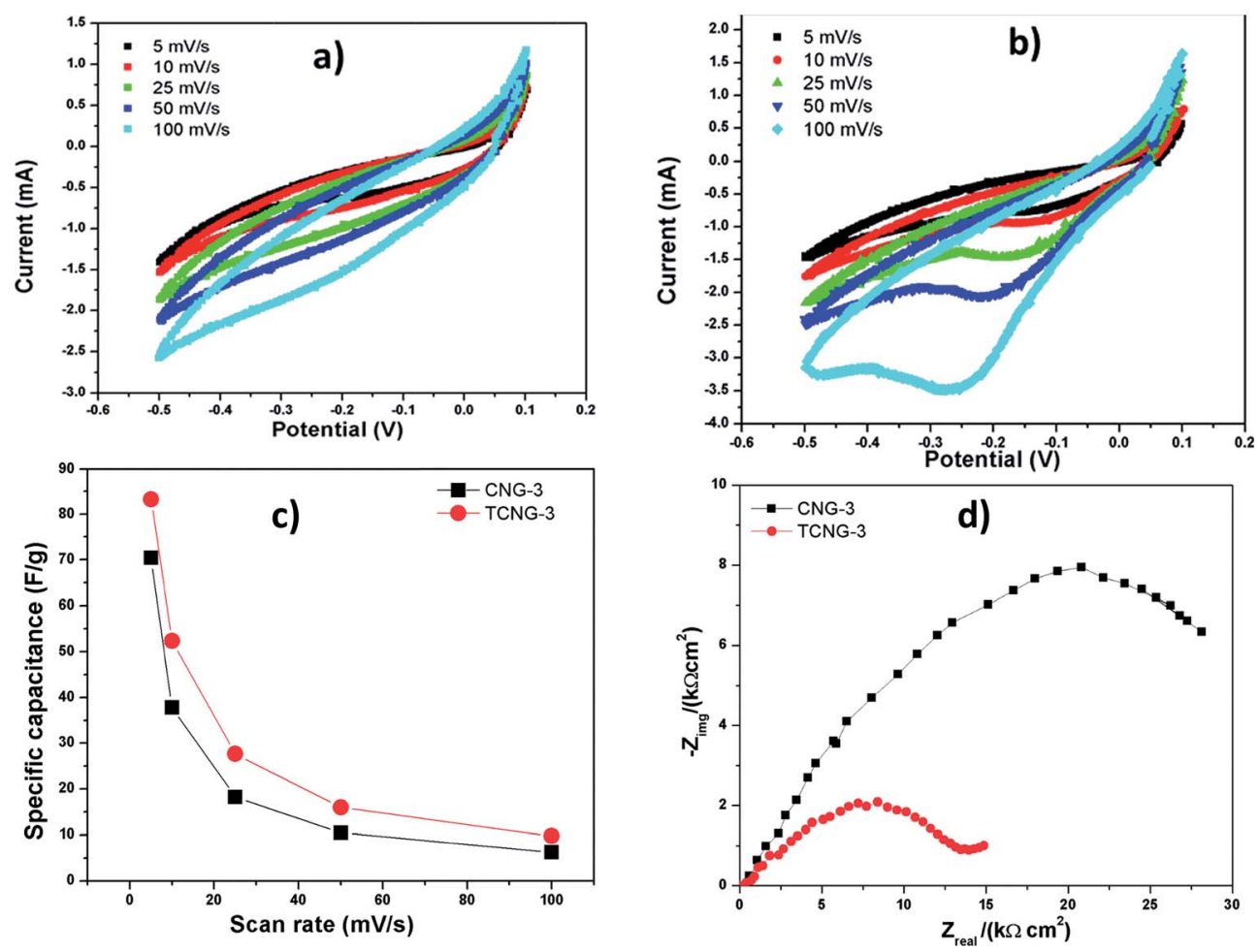

Fig. 10 Cyclic voltammograms of CNG-3 (a) and TCNG-3 (b); specific capacitance (c) of CNG-3 and TCNG-3 composite films as working electrodes with different scan rates; (d) Nyquist spectra for CNG-3 and TCNG-3.

electrical circuit, where $W$ stands for the semi-infinite (unrestricted) layer thickness diffusion.

Even in the absence of highly conducting materials and porous networks, which give greater specific surface area, the CNF and TCNF electrode films achieve better capacitive performance using relatively small amounts of NGO. Overall, our nanocomposites have a high dielectric response and are suitable candidates for potential applications in high charge storage capacitors.

\section{Conclusions}

Flexible eco-friendly nanocomposite films were fabricated by incorporating ammonia-functionalized graphene oxide (NGO) into the native (CNF) and TEMPO-oxidized (TCNF; carboxylated) cellulose nanofibrils matrices using a solvent casting method. The reduced wettability and increased smoothness of the films' surfaces, as well as increased mechanical strength and thermal stability, are in good agreement with the increased (0.5-3 wt\%) NGO loading concentrations. This is revealed by the low aggregation and good dispersibility within the CNFs matrix, being improved further within more densely and horizontally-orientated TCNFs, due to increased physicochemical interactions with the NGO nanosheets. Besides, the high dielectric constant and AC conductivity at a relatively high-frequency region $(1 \mathrm{MHz})$, with comparable electrochemical energy storage capacity demonstrated that such ultra-strong and ultra-stiff composite films are suitable, cost- effective, alternative green materials for flexible energy storage devices.

\section{Acknowledgements}

The work was supported financially by the Erasmus Mundus project Euphrates (2013-2540/001-001-EMA2).

\section{Notes and references}

1 Y. Wang, Chem. Soc. Rev., 2015, 44, 5181-5199.

2 C.-Y. Wang, C. Fuentes-Hernandez, J.-C. Liu, A. Dindar, S. Choi, J. P. Youngblood, R. J. Moon and B. Kippelen, ACS Appl. Mater. Interfaces, 2015, 7, 4804-4808.

3 G. Yang, C. Lee, J. Kim, F. Ren and S. J. Pearton, Phys. Chem. Chem. Phys., 2013, 15, 1798-1801.

4 Z. Weng, Y. Su, D.-W. Wang, F. Li, J. Du and H.-M. Cheng, Adv. Energy Mater., 2011, 1, 917-922.

5 T. Inui, H. Koga, M. Nogi, N. Komoda and K. Suganuma, $A d v$. Mater., 2015, 27, 1112-1116.

6 A. Kafy, K. K. Sadasivuni, H. Kim, A. Akther and J. Kim, Phys. Chem. Chem. Phys., 2015, 17, 5923-5931.

7 M. Tian, L. Qu, X. Zhang, K. Zhang and S. Zhu, Carbohydr. Polym., 2014, 111, 456-462.

8 D. R. Dreyer, S. Park, C. W. Bielawski and R. S. Ruoff, Chem. Soc. Rev., 2010, 39, 228-240.

9 D. C. Marcano, D. V Kosynkin, J. M. Berlin, A. Sinitskii, Z. Sun, A. Slesarev, L. B. Alemany, W. Lu and J. M. Tour, ACS Nano, 2010, 4, 4806-4814. 
10 K. S. Novoselov, A. K. Geim, S. V. Morozov, D. Jiang, Y. Zhang, S. V. Dubonos, I. V. Grigorieva and A. A. Firsov, Science, 2004, 306, 666-669.

11 L. Valentini, M. Cardinali, E. Fortunati, L. Torre and J. M. Kenny, Mater. Lett., 2013, 105, 4-7.

12 B. Wang, W. Lou, X. Wang and J. Hao, J. Mater. Chem., 2012, 22, 12859.

13 L. Yao, Y. Lu, Y. Wang and L. Hu, Carbon, 2014, 69, 552-562.

14 M. Mohiuddin, K. K. Sadasivuni, S. Mun and J. Kim, RSC Adv., 2015, 5, 34432-34438.

15 K. K. Sadasivuni, A. Kafy, H.-C. Kim, H.-U. Ko, S. Mun and J. Kim, Synth. Met., 2015, 206, 154-161.

16 T. Saito, S. Kimura, Y. Nishiyama and A. Isogai, Biomacromolecules, 2007, 8, 2485-2491.

17 H. Fukuzumi, T. Saito, T. Iwata, Y. Kumamoto and A. Isogai, Biomacromolecules, 2009, 10, 162-165.

18 H. Yagyu, T. Saito, A. Isogai, H. Koga and M. Nogi, ACS Appl. Mater. Interfaces, 2015, 7, 22012-22017.

19 H. Zhu, Z. Xiao, D. Liu, Y. Li, N. J. Weadock, Z. Fang, J. Huang and L. Hu, Energy Environ. Sci., 2013, 6, 2105.

20 A. Isogai, T. Saito and H. Fukuzumi, Nanoscale, 2011, 3, 7185.

$21 \mathrm{~S}$. Iwamoto, W. Kai, A. Isogai and T. Iwata, Biomacromolecules, 2009, 10, 2571-2576.

22 T. Saito, Y. Nishiyama, J.-L. Putaux, M. Vignon and A. Isogai, Biomacromolecules, 2006, 7, 1687-1691.

23 T. Tadros, J. Chem. Technol. Biotechnol., 1995, 64, 311.

24 C. J. Van Oss, M. K. Chaudhury and R. J. Good, Chem. Rev., 1988, 88, 927-941.

25 M. Fan, D. Dai and B. Huang, Fourier Transform Infrared Spectroscopy for Natural Fibres in Fourier Transform Materials Analysis, ed. Salih Mohammed Salih, ISBN 978953-51-0594-7, May 23, 2012, DOI: 10.5772/35482.

26 R. Kabiri and H. Namazi, Cellulose, 2014, 21, 3527-3539.
27 B. J. Ryan and K. M. Poduska, Am. J. Phys., 2008, 76, 1074.

28 A. B. D. Cassie and S. Baxter, Trans. Faraday Soc., 1944, 40, 546.

29 T. Mohan, R. Kargl, A. Doliška, A. Vesel, S. Köstler, V. Ribitsch and K. Stana-Kleinschek, J. Colloid Interface Sci., 2011, 358, 604-610.

30 C.-J. Kim, W. Khan, D.-H. Kim, K.-S. Cho and S.-Y. Park, Carbohydr. Polym., 2011, 86, 903-909.

31 D. Han, L. Yan, W. Chen, W. Li and P. R. Bangal, Carbohydr. Polym., 2011, 83, 966-972.

32 M. El Achaby, N. El Miri, A. Snik, M. Zahouily, K. Abdelouahdi, A. Fihri, A. Barakat and A. Solhy, J. Appl. Polym. Sci., 2016, 133(2), 42356.

33 Q. Zheng, Z. Cai, Z. Ma and S. Gong, ACS Appl. Mater. Interfaces, 2015, 7, 3263-3271.

34 P. C. P. Watts, W.-K. Hsu, A. Barnes and B. Chambers, Adv. Mater., 2003, 15, 600-603.

35 Y. Li, Y. Shi, F. Cai, J. Xue, F. Chen and Q. Fu, Composites, Part A, 2015, 78, 318-326.

36 K. K. Sadasivuni, D. Ponnamma, B. Kumar, M. Strankowski, R. Cardinaels, P. Moldenaers, S. Thomas and Y. Grohens, Compos. Sci. Technol., 2014, 104, 18-25.

37 P. Lunkenheimer, V. Bobnar, A. V. Pronin, A. I. Ritus, A. A. Volkov and A. Loidl, Phys. Rev. B: Condens. Matter Mater. Phys., 2002, 66, 052105.

38 P. Yang and W. Mai, Nano Energy, 2014, 8, 274-290.

39 G.-W. Yang, C.-L. Xu and H.-L. Li, Chem. Commun., 2008, 6537-6539.

40 D. Ge, L. Yang, L. Fan, C. Zhang, X. Xiao, Y. Gogotsi and S. Yang, Nano Energy, 2015, 11, 568-578.

41 G. Zu, J. Shen, L. Zou, F. Wang, X. Wang, Y. Zhang and X. Yao, Carbon, 2016, 99, 203-211.

42 E. Barsoukov and J. R. Macdonald, Impedance Spectroscopy, 2005. 